\title{
The calculation of the field of an antenna located near the human head
}

\author{
Hamood Shehab Hamid ${ }^{1}$, Raad Farhood Chisab ${ }^{2}$ \\ ${ }^{1}$ Department of Computer Engineering Techniques, Electrical Engineering Technical College, Middle Technical \\ University, Baghdad, Iraq \\ ${ }^{2}$ Department of Electrical Techniques, Technical Institute-Kut, Middle Technical University, Baghdad, Iraq
}

\begin{tabular}{l} 
Article Info \\
\hline Article history: \\
Received Jul 10, 2021 \\
Revised Sep 9, 2021 \\
Accepted Oct 16, 2021 \\
\hline
\end{tabular}

Keywords:

Antenna

GSM

Human head

Radiation

SAR

\begin{abstract}
In this work, a numerical calculation was carried out in one of the universal programs for automatic electro-dynamic design. The calculation is aimed at obtaining numerical values for specific absorbed power (SAR). It is the SAR value that can be used to determine the effect of the antenna of a wireless device on biological objects; the dipole parameters will be selected for GSM1800. Investigation of the influence of distance to a cell phone on radiation shows that absorbed in the head of a person the effect of electromagnetic radiation on the brain decreases by three times this is a very important result the SAR value has decreased by almost three times it is acceptable results.
\end{abstract}

This is an open access article under the CC BY-SA license.

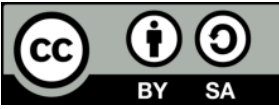

\section{Corresponding Author:}

Raad Farhood Chisab

Department of Electrical Techniques

Technical Institute-Kut, Middle Technical University

Muasker Al Rashid Street, Baghdad, Iraq

Email: raad.farhood@mtu.edu.iq, raadfarhood@yahoo.com

\section{INTRODUCTION}

In the near zone of the antenna, there are other radio-technical parts of the device, which significantly affected by the electromagnetic field [1]. There is a need to solve the problem of electromagnetic compatibility. One of the methods is to create such a spatial structure of the near-field of the antenna, in which the minimum (or minima) of the field will coincide with the main radio-technical units of the device, the most sensitive in the external electromagnetic field [2]. An urgent problem is the creation of small-sized antennas with special properties, in particular, providing a certain field structure in the near-field zone of the antenna. As you know, the attenuation of electromagnetic waves in space depends on the distance from the emitter to the object [3].

Since cellular devices are in close proximity to a person throughout the day, their radiation makes up a significant part of the entire electromagnetic influence of the modern world on a person (towers of radio television stations, power lines, Wi-Fi antennas, etc. Other wireless devices, household electrical appliances, cellular stations). To date, scientists have not come to a consensus on the effect of electromagnetic radiation from cellular devices on the human body [4]. Numerous studies on biological objects carried out by scientists from different countries, including Russia and Malaysia have led to ambiguous, sometimes conflicting results. The only undeniable fact remains that the human body reacts to the presence of radiation from a cell phone. About half of the radiated power of a modern cell phone during a conversation absorbed by the head, in which electromagnetic energy converted into heat [5]. According to [6], the energy losses of the 
electromagnetic field of a cell phone in the user's head range from $40 \%$ to $68 \%$, it is also stated that the radiation mainly absorbed by the brain. In addition to the thermal effect of a cell phone on the brain, there is an equally significant factor.

The brain is the center of the body that sends electrical signals throughout the body, and most of the processes in it occur due to the formation of temporary electronic circuits (circuits). Since the control electrical impulses are of low power [7], the source of electromagnetic radiation (which is constantly in the pocket of trousers or on the chest) with a power of up to 2 Watt cannot but have a pathogenic effect on the human body [8]. The radiation source, acting on the head, begins to influence both the organization of thought processes (higher nervous activity) and the transmission of signals to all human organs [9]. This can lead to changes in the activity of the brain: memory deteriorates, attention is weakened, irritability and fatigue increase [10].

This year, the World Health Organization classified radiation from cell phone antennas to the list of carcinogens-external factors that influence the development of cancer, in particular brain cancer [11]. For these reasons [12], attenuation of radiation from a cell phone in the head area is a rather urgent problem. One of the ways to protect the brain from the electromagnetic field is the use of shielding, ie using the shading effect. The shadow behind the metal screen extends over a distance of the order of the screen size [13]. To protect the entire head area, it is possible to suggest the use of an absorber, ie. a dielectric screen that absorbs some of the energy. In this case, it is necessary to take into account the effect on the radiation pattern and on radiation losses both in the screen and in the head [14].

In this paper, we consider a more general problem of forming the electric field zeroes by a system of a finite number of emitters, from two or more [15]. The purpose of the work is to investigate the possibility of creating an area with a minimum value of the electromagnetic field near the user and at the same time to form the directional pattern necessary to ensure communication at large distances from the user [16]. This approach seems to be promising not only for antennas of cell phones, but also for other devices (wireless systems of laptops, wireless headsets placed near the human body, etc.), and can also find application in solving problems of electromagnetic compatibility various radio facilities [17].

\section{RESEARCH METHOD}

\subsection{Broblem formulation}

The protective effect of an additional antenna or a system of antennas studied, in this work based on a different principle-on mutual suppression in a certain region of the fields generated by different radiating elements [18]. The method of suppressing the electromagnetic field in a given area consists in creating in this area a field from the additional antenna equal in magnitude and opposite in phase to the field from the main radiating antenna [19]. As a result, interference zeros appear in space, significantly reducing absorption indices of the electromagnetic field in the area nearest to them [20].

The formation of such interference zeros is discussed in [21], [22] for example of, a Huygens element with an arbitrary ratio of currents and in [23], [24] for a system of two parallel electric dipoles (vibrators). The formation of the fixed zeros of the electric field at a finite distance from the system of radiators carried out by selecting the amplitude and phase difference of their currents [25]. The effectiveness of interference suppression lies in its main property: if two signals of the same amplitude interfere, then when adding in phase at a given point, the power rises to $3 \mathrm{~dB}$, and in antiphase it is suppressed to minus infinity $\mathrm{dB}[26]$, [27].

\subsection{Software setup}

While HFSS implements of the finite element method (FEM), the field arrangements found from Maxwell's conditions precisely foresee all scattering attributes existing and changes of wave types, losses in materials and radiation. Despite the advantages that Microwave Office and FEKO have in solving electrodynamics three dimensional problems. The primary element of the FEKO program that recognizes it from comparative items (Microwave Office, HFSS, and so forth) is the effective blend of mathematical techniques for tackling three dimensional electrodynamics issues such as the method of moments (Mom), the method of physical optics (MFO) and homogeneous diffraction theory (OTD), [27]. Disadvantages appear like other programs in case computer modeling for high frequencies [28].

The CST software contains four different simulation methods: transient analysis, frequency domain, analysis eigenvalue (solution) determination, and wave form analysis solver. The environment was developed taking into account the ever-increasing requirements for the complexity of simulated effects and their interrelations: Mixed analysis of electrical circuits and EM structures, Thermal analysis of electrical losses, Analysis of the behavior of charged particles in a static or resonant field, magneto static analysis of field currents. The ability of the program to work with dielectric materials, which are models of biological tissues, is important for us. The calculation of SAR in such dielectric structures is possible in CST. Also, CST can 
use the equations of thermal conductivity; find the heating of biological objects as a result of the action of the electromagnetic field from microwave structures [29]. Therefore, in subsequent calculations, we will use this program.

\subsection{The proposed modeling design}

\subsubsection{Calculations near-field antenna model}

From the standpoint of the World Health Organization, the main influence on a person is exerting by the absorption of the energy of the electric field in human tissues. Thus, in practice [30], the task is to reduce the heating of biological objects. Heating of biological objects depends mainly on the electrical component of the electromagnetic field. Therefore, it is sufficient to investigate only this component of the electromagnetic field [31]. The solution to this problem for elementary radiators can be generalized for more complex antenna systems. This is possible, since the formation of the field in these structures is carried out in the same way as in a conventional dipole [32]. A numerical an antenna located modeling design near the human head considered a layered spherical head model. Geometrical and electro dynamic parameters of each layer are, choosen Substance for brain, bone and leather, the central layer is representing by a substance with characteristics similar to those of the human brain. The next layer is a model of the skull - the bone tissue of the human head, which is covering by the last layer with dielectric parameters equal to those of human skin, also, there is an ear "composed of skin and shaped like a parallelepiped.

\subsubsection{Calculations near the human head model over two bands frequency 900 and $1800 \mathrm{MHz}$}

Modeling, in this research, it decided not to carry out the formation of a more complex shape of the ear, since the head model is rather rough, in addition to a human head model, a model of a cellular telephone which is a body made of plastic, and a dipole antenna behind this body. To simplify modeling and further calculation, we take a symmetrical vibrator as a model of a cell phone antenna [33]. Global System for Mobile Communications (GSM) uses 2 frequency bands 900 and 1800 MHz. GSM 900 - used in urban environments vii, GSM 1800 - on a more open, countryside. To be specific "we will consider all processes at a higher frequency-1800 MHz.

In the CST program, we will experimentally select the dipole parameters for GSM1800, the arm length and radius, such that the reflection coefficient at the frequency under consideration is minimal. These parameters turned out to be equal to the following values: $\mathrm{L}$ (dipole arm length) $=35 \mathrm{~mm}$, $\mathrm{R}$ (dipole radius) $=1$ $\mathrm{mm}, \mathrm{d}$ (distance at the feeding point between the arms) $=2 \mathrm{~mm}$. The value of the reflection coefficient from such dipole onto free space is showing in Figure 1.

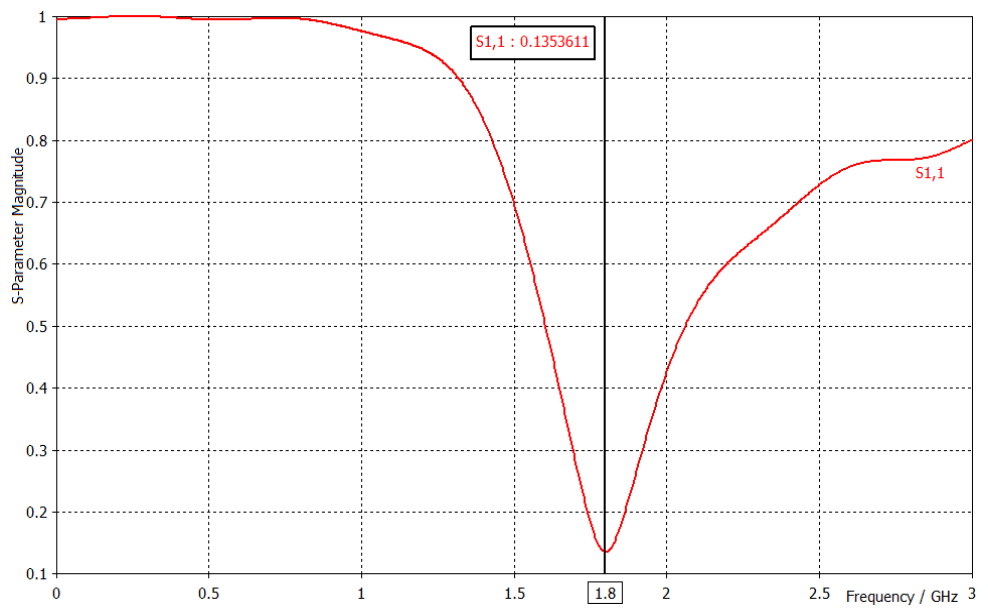

Figure1. Coefficient of reflection, loaded on free space, calculated in CST

Let us compare the results with a simpler approximation by the formulas in the book by G. T. Markov Antennas [34]. Comparative analysis of Figure 2 shows that the calculation of the reflection coefficient in the CST medium is in good agreement with the approximate solution. Small changes in the approximate solution are associated with the simplicity of the model, which does not take into account the distance between the vibrator arms such a dipole loaded onto free space [35], is shown in Figure 2. 


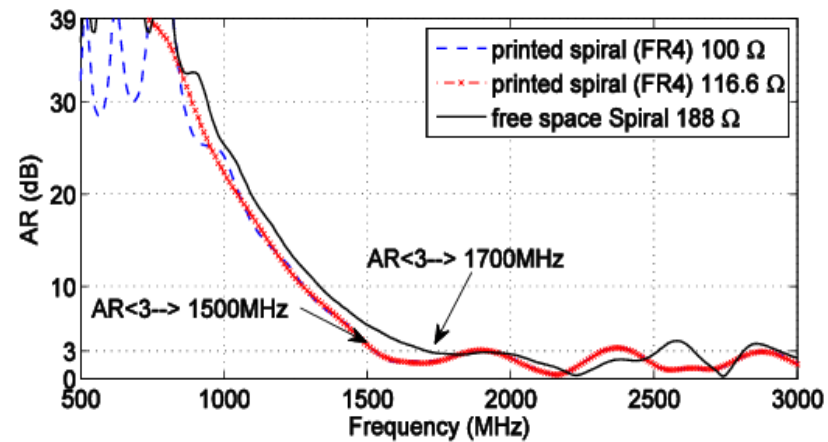

Figure 2. Calculated axial ratio elementary spiral antenna

\section{RESULTS AND DISCUSSION}

The use of Microsoft Equation Editor or MathType is preferred. An investigation of the influence of distance to a cell phone on radiation absorbed in the head of a person let's consider in three cases. The first case: When the phone model is pressed close to the ear. A dielectric head form inserted into the near field affects antenna matching [36]. The resonant frequency value has decreased by $13 \%$ compared to empty space. The strength of the electric field penetrating into the center of the model is $50 \mathrm{~V} / \mathrm{m}$. The maximum value of the surface specific absorbed power is $9.29 \mathrm{~W} / \mathrm{kg}$ as shown as in Figure 3.

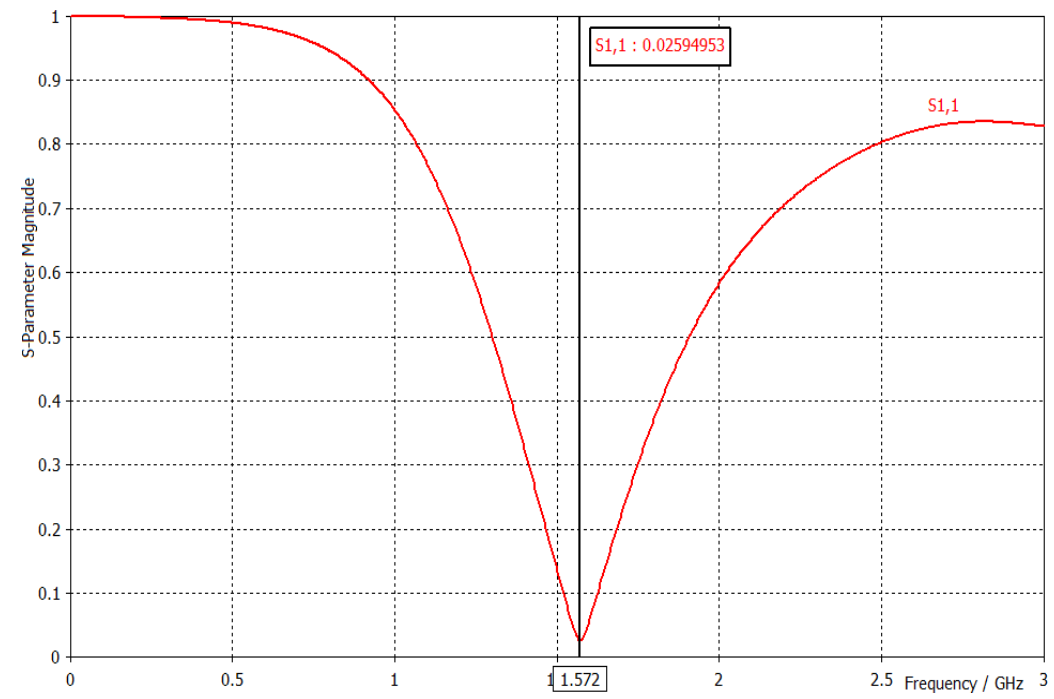

Figure 3. Ear distance-0 mm, resonance frequency-1.572 GHz, the reflection coefficient at the resonant frequency is 0.026 , the maximum surface SAR value is $9.29 \mathrm{~W} / \mathrm{kg}$

The second case: the phone model is positioned $5 \mathrm{~mm}$ from ear. The value of the resonant frequency decreased by $8 \%$ compared to empty space. The changes in the resonant frequency are less than in the first case, which means a decrease in the influence of the head of the antenna with an increase in the distance between them. The strength of the electric field penetrating into the center of the model is $45 \mathrm{~V} / \mathrm{m}$. The maximum value of the surface specific absorbed power-5.74 W/kg SAR value in comparison with the first case decreased by one third as shown as in Figure 4. The third case: The phone model is positioned $10 \mathrm{~mm}$ from ear. The resonant frequency value has decreased by $9 \%$ compared to the empty probe. The strength of the electric field penetrating into the center of the model is $40 \mathrm{~V} / \mathrm{m}$. The maximum value of the surface specific absorbed power is $3.45 \mathrm{~W} / \mathrm{kg}$. The SAR value in comparison with the first case has decreased by almost three times. This is a very important result. The loudspeaker's audibility at a distance of $10 \mathrm{~mm}$ is acceptable, and the effect of electromagnetic radiation on the brain decreases by 3 times as shown as in Figure 5. 


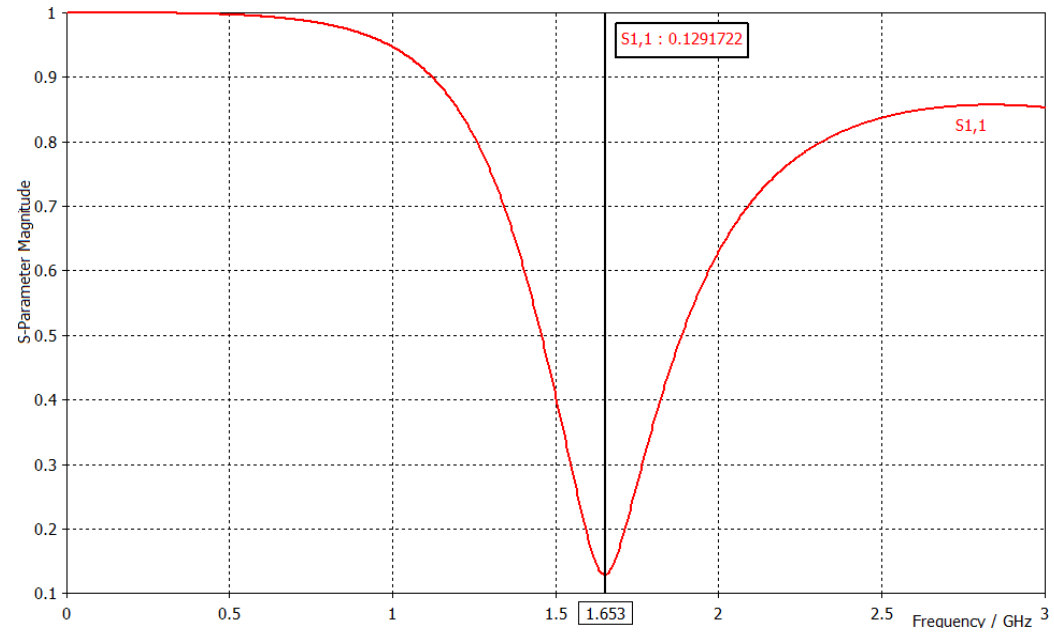

Figure 4. Ear distance-5 mm, resonance frequency-1.653 GHz, the reflection coefficient at the resonant frequency is 0.13 , the maximum surface $\mathrm{SAR}$ is $5.74 \mathrm{~W} / \mathrm{kg}$

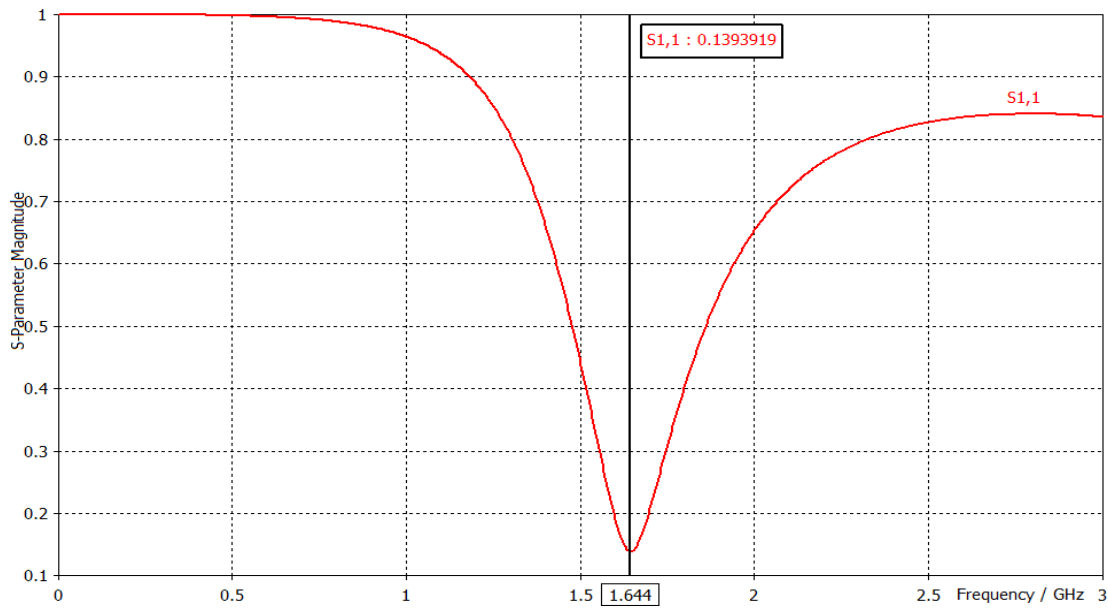

Figure 5. Ear distance-10mm, the resonant frequency is $1.644 \mathrm{GHz}$, the reflectance coefficient at the resonant frequency is 0.14 , the maximum surface $\mathrm{SAR}$ is $3.45 \mathrm{~W} / \mathrm{kg}$

\section{CONCLUSION}

Modeling and the numerical solution of the influence of a cell phone antenna on a biological object (human head model) were carried out. Analysis of results obtained that, the specific power absorbed by the human head decreases three times, at a distance of the telephone antenna by $10 \mathrm{~mm}$. Comparative analysis shows that the calculation of the reflection coefficient in the CST medium is in good agreement with the approximate solution. The problem of how to reduce the negative influence of the radiation from the antibrain to the brain and other fires of the user at the time of the conversation and the transfer of the current Phone. In future works and on the basis of elemental sources, this is the task, and the search for a possible solution of the given task carried out Use of elemental transmitters, instead of other reality, runs the modeling and calculates, along with that, the given solution is to try to play on up-to-date constructions (as well as or, in their main, there is a common vibrator)

\section{REFERENCES}

[1] N. I. Zaidi, M. T. Ali, N. H. Abd Rahman, M. F. Yahya and M. S. Amin Nordin, "Analysis on different shape of textile antenna under bending condition for GPS application," Bulletin of Electrical Engineering and Informatics, vol. 9, pp. 1964-1970, 2020, doi: 10.11591/eei.v9i5.2185. 
[2] S. M. Shah et al., "A compact dual-band semi-flexible antenna at $2.45 \mathrm{GHz}$ and $5.8 \mathrm{GHz}$ for wearable applications," Bulletin of Electrical Engineering and Informatics, vol. 10, pp. 1739-1746, 2021, doi: 10.11591/eei.v10i3.2262.

[3] L. Ukkonen, L. Sydänheimo, T. Björninen and S. Ma, "Antennas and Wireless Power Transfer for BrainImplantable Sensors," in Antenna and Sensor Technologies in Modern Medical Applications, 2021. ch4. IEEE, 2021, pp.91-143, doi: 10.1002/9781119683285.ch4.

[4] M. K. Woo et al., "Comparison of 16-Channel Asymmetric Sleeve Antenna and Dipole Antenna Transceiver Arrays at 10.5 Tesla MRI," IEEE Transactions on Medical Imaging, vol. 40, no. 4, pp. 1147-1156, April 2021, doi: 10.1109/TMI.2020.3047354.

[5] K. Masumnia-Bisheh and C. Furse, "Estimating the Variance of SAR in a 3D Human Head Model Using Stochastic FDTD," 2020 IEEE International Symposium on Antennas and Propagation and North American Radio Science Meeting, 2020, pp. 1989-1990, doi: 10.1109/IEEECONF35879.2020.9330224.

[6] M. K Abdulhameed, M. S. Mohamad Isa, Z. Zakaria, I.M. Ibrahim and Mowafak K. Mohsen, "Radiation pattern control of microstrip antenna in elevation and azimuth planes using EBG and pin diode," International Journal of Electrical and Computer Engineering, vol. 9, pp. 332-340, 2019, doi: 10.11591/ijece.v9i1.pp332-340.

[7] H. Shehab, W. Ismail and M. Singh, "Low power FSK detection at low probability bit- errors," 2008 International Conference on Electronic Design, 2008, pp. 1-4, doi: 10.1109/ICED.2008.4786760.

[8] C. Y. Saw, Y. C. Wong, S. L. Loh and H. Zhang, "On-chip ultra-low power optical wake-up receiver for wireless sensor nodes targeting structural health monitoring," TELKOMNIKA Telecommunication, Computing, Electronics and Control, vol. 18, pp. 2257-2264, 2020, doi: 10.12928/telkomnika.v18i5.13378.

[9] M. T Ali, Y. R Muhsen, R. F. Chisab and S. N Abed, "Evaluation Study of Radio Frequency Radiation Effects from Cell Phone Towers on Human Health," Radioelectronics and Communications Systems, vol. 64, no. 3, pp. 155-164, 2021, doi: 10.3103/S0735272721030055.

[10] R. F. Chisab, "An active technique for power saving in WSN under additive white gaussian noise channel," International Journal of Electrical \& Computer Engineering, vol. 9, no. 1, pp. 386-396, 2019, doi: 10.11591/ijece.v9i1.pp386-396.

[11] A. Singla, A. Marwaha and S. Marwaha, "Reduction of specific absorption rate (SAR) for human head using circular patch antenna," 2020 7th International Conference on Signal Processing and Integrated Networks (SPIN), 2020, pp. 189-192, doi: 10.1109/SPIN48934.2020.9071274.

[12] S. M. Rao and P. I. Basarkod, "A multiband patch antenna with embedded square split ring resonators in nonHomogeneous substrate," Bulletin of Electrical Engineering and Informatics, vol. 10, pp. 1423-1435,2021, doi: 10.11591/eei.v10i3.2556.

[13] R. F. Chisab and C. K. Shukla, "The Downlink 4G-LTE in Fading Channel Based on the Multiwavelet Transform," 2014 International Conference on Computational Intelligence and Communication Networks, 2014, pp. 233-236, doi: 10.1109/CICN.2014.61.

[14] I. B. Oluwafemi, A. M. Faluru and T. D. Obasanyo, "Radio frequency peak and average power density from mobile base stations in Ekiti State, Nigeria," Bulletin of Electrical Engineering and Informatics, vol. 10, pp. 224-231, 2021, doi: 10.11591/eei.v10i1.1879.

[15] H. Mansor, M. H. Norhisam, Z. Z. Abidin and T. S. Gunawan, "Autonomous surface vessel for search and rescue operation," Bulletin of Electrical Engineering and Informatics, vol. 10, pp. 1701-1708, 2021, doi: 10.11591/eei.v10i3.2599.

[16] A. S. M. Alqadami, N. Nguyen-Trong, B. Mohammed, A. E. Stancombe, M. T. Heitzmann and A. Abbosh, "Compact Unidirectional Conformal Antenna Based on Flexible High-Permittivity Custom-Made Substrate for Wearable Wideband Electromagnetic Head Imaging System," IEEE Transactions on Antennas and Propagation, vol. 68, no. 1, pp. 183-194, Jan. 2020, doi: 10.1109/TAP.2019.2938849.

[17] S. M. Shah et al., "A $2.45 \mathrm{GHz}$ microstrip antenna with harmonics suppression capability by using defected ground structure," Bulletin of Electrical Engineering and Informatics, vol. 9, no. 1, pp. 387-395, 2020, doi: 10.11591/eei.v9i1.1847.

[18] M. F. E. Purnomo et al., "Development of patch stack antenna for CP-SAR sensor," Bulletin of Electrical Engineering and Informatics, vol. 10, no. 1, pp. 2302-9285, 2021, doi: 10.11591/eei.v10i1.2672.

[19] M. M. Jawad, N. N. N. A. Malik, N. A. Murad, M. R. Ahmad, M. R. M. Esa and Y. M. Hussein, "Design of substrate integrated waveguide with Minkowski-Sierpinski fractal antenna for WBAN applications," Bulletin of Electrical Engineering and Informatics, vol. 9, pp. 2455-2461, 2020, doi: 10.11591/eei.v9i6.2194.

[20] A. R. O. Mumin, R. Alias, J. Abdullah, S. H. Dahlan, J. Ali and S. K. Debnath, "Design a compact square ring patch antenna with AMC for SAR reduction in WBAN applications," Bulletin of Electrical Engineering and Informatics, vol. 9, no. 1, pp. 370-378, 2020, doi: 10.11591/eei.v9i1.1686.

[21] A. Z. El Dein and A. Amr, "Specific absorption rate (SAR) induced in human heads of various sizes when using a mobile phone," 2010 7th International Multi-Conference on Systems, Signals and Devices, 2010, pp. 1-6, doi: 10.1109/SSD.2010.5585549.

[22] A. Y. Iliyasu, M. R. Hamid, M. K. A. Rahim, M. F. M. Yusoff, M. Aminu-Baba and M. M. Gajibo, "Wideband frequency -reconfigurable metamaterial antenna design with double $\mathrm{H}$ slots," Bulletin of Electrical Engineering and Informatics, vol. 9, no. 5, pp. 1971-1978, 2020, doi: 10.11591/eei.v9i5.2193.

[23] A. Y. I. Ashyap et al., "Fully Fabric High Impedance Surface-Enabled Antenna for Wearable Medical Applications," in IEEE Access, vol. 9, pp. 6948-6960, 2021, doi: 10.1109/ACCESS.2021.3049491. 
[24] S. K. Sharma, A. Gupta and R. K. Chaudhary, "Epsilon Negative CPW-Fed Zeroth-Order Resonating Antenna With Backed Ground Plane for Extended Bandwidth and Miniaturization," in IEEE Transactions on Antennas and Propagation, vol. 63, no. 11, pp. 5197-5203, Nov. 2015, doi: 10.1109/TAP.2015.2477521.

[25] S. R. A. Mutalik, M. H. Mat, M. Jusoh and A. W. N. Husna, "A study of specific absorption rate in human head due to electromagnetic exposure to 4G signals," Indonesian Journal of Electrical Engineering and Computer Science, vol. 13, pp.1161-1166, 2019, doi: 10.11591/ijeecs.v13.i3.pp1161-1166.

[26] H. H. Keriee and M. K. A. Rahim, "High gain antenna at $915 \mathrm{MHz}$ for off grid wireless networks," Bulletin of Electrical Engineering and Informatics, vol. 9, no. 6, pp. 2449-2454, 2020, doi: 10.11591/eei.v9i6.2192.

[27] M. Y. Zeain et al., "Design of a wideband strip helical antenna for 5G applications," Bulletin of Electrical Engineering and Informatics, vol. 9, no. 5, pp. 1958-1963, 2020, doi: 10.11591/eei.v9i5.2055.

[28] I. Ali, M. H. Jamaluddin, M. R. Kamarudin, A. Gaya and R. Selvaraju, "Wideband and high gain dielectric resonator antenna for 5G applications," Bulletin of Electrical Engineering and Informatics, vol. 8, no. 3, pp. 10471052, 2019, doi: 10.11591/eei.v8i3.1592.

[29] Md. S. Islam, M. I. Ibrahimy, S. M. A. Motakabber, A. K. M. Z. Hossain and S. M. K. Azam, "Microstrip patch antenna with defected ground structure for biomedical application," Bulletin of Electrical Engineering and Informatics, vol. 8, no. 2, pp. 586-595, 2019, doi: 10.11591/eei.v8i2.1495.

[30] CST STUDIO SUITE 2016, "Microwave - Radio Frequency - Optical," 2016.

[31] K. Ali, N. A. Malek, A. Z. Jusoh, S. Y. Mohamad, Z. Z. Abidin and A. L. Asnawi, "Design and optimize microstrip patch antenna array using the active element pattern technique," Bulletin of Electrical Engineering and Informatics, vol. 8, no. 3, pp. 994-1003, 2019, doi: 10.11591/eei.v8i3.1516.

[32] N. I. A. Ishak, N. Seman and N. A. Samsuri, "Specific Absorption Rate Assessment of Multiple Microstrip Patch Antenna Array" TELKOMNIKA Telecommunication, Computing, Electronics and Control, vol. 16, no. 4, pp. 15001507, 2018, doi: 10.12928/telkomnika.v16i4.9041.

[33] A. R. O. Mumi, R. Alias, J. Abdullah, S. H. Dahlan and J. Ali, "Assessment of Electromagnetic Absorption towards Human Head Using Specific Absorption Rate,” Bulletin of Electrical Engineering and Informatics, vol. 7, no. 4, pp. 657-664, 2018, doi: 10.11591/eei.v7i4.1357.

[34] S. Barigidad, A. C. Yeshawant, S. Rao, Tharunya C. A., T. Ali and S. Pathan, "A triple band modified F-shaped monopole antenna for RFID application," Bulletin of Electrical Engineering and Informatics, vol. 9, no. 6, pp. 2469-2476, 2020, 10.11591/eei.v9i6.2623.

[35] G.T. Markov and D.M. Sazonov, "Antennas: Tutorial for students of radio engineering," Moscow: Moscow, 1975.

[36] A. Ennajih, B. Nasiri, J. Zbitou, A. Errkik and M. Latrach, "A wearable UHF RFID tag antenna-based metamaterial for biomedical applications," Bulletin of Electrical Engineering and Informatics, vol. 9, no. 2, pp. 676-684, 2020, doi: 10.11591/eei.v9i2.1661

\section{BIOGRAPHIES OF AUTHORS}
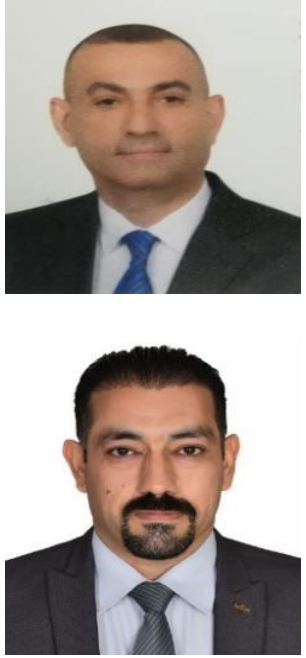

Dr. Hamood Shehab Hamid received his B.Sc. in Collage of Electrical \& Electronic Engineering, University of Sarajevo, 1986, Sarajevo -Bosnia's Republic. Received the M.Sc. degree in Electronic \& Communications Engineering, Electrical \& Electronic Engineering College, Belgrade University, The republic of Serbia 1988. He received his Ph.D. in Wireless and Mobile Communication Systems from School of Electronic Engineering, University Sains Malaysia (USM), Pinang-Malaysia. 2011. He is currently a faculty member at Electrical Engineering Technical College, Middle Technical University, Department of Computer Engineering Techniques, Baghdad/Iraq. Email: drhamood@mtu.edu.iq

Dr. (Eng.) Raad Farhood Chisab was born in Baghdad-Iraq at 1975. He received the B.Sc. in Electrical Engineering and M.Sc. degree in control and computer engineering from College of Engineering-University of Baghdad. At 2015 the author gets his Ph.D. degree in Electronic and Communication Engineering from SHIATS University, INDIA. From $2005 \mathrm{He}$ works as lecturer, researcher and training supervisor in the Ministry of Higher Education and Scientific Research-Middle Technical University-Baghdad. His research interest includes signal processing, image processing, wireless communication, mobile technology, wireless sensor network, IOT, 4G and 5G Technology. The author published about 20 papers in national and international journals. E-mail:raadfarhood@yahoo.com,raad.farhood@mtu.edu.iq 